\title{
Analysis of a building collapse: An examination of investigation methodology
}

Received (in revised form): 6th November, 2006

\section{Malcolm Hollis}

is Professor of Building Pathology at The University of Reading as well as being a practitioner. Malcolm Hollis Chartered Surveyors is a surveying practice with representation throughout England.

Correspondence: Malcolm Hollis, Chartered Surveyor and Building Pathologist, 6 Rydal Road, London SW16 1QN, UK; Tel: +44 0208769 9927; Fax: +44 0208769 2670; E-mail: mh@malcolmhollis.org

\section{Abstract}

The collapse of a 26-year-old office building in 1995 raised questions about the discoverability of the condition of a building and the risks inherent in remedial work. The failure to discover the errors in the original construction resulted in the loss of the lives of four people working within the building when it collapsed. The subsequent court case determined that liability fell on those who were involved in the original construction of the building in 1969. The Court decided that 26 years after being responsible for the design and management, ultimate responsibility rested upon the shoulders of the original company who developed the land, even though they had engaged independent builders to erect this building. The investigation into the cause of the collapse revealed the limited value of the original drawings, the problems caused because a collapsed building is not treated as a crime scene, the merits of a systematic deconstruction of the remaining building, and the benefits and weaknesses of the methodology adopted.

Journal of Building Appraisal (2006) 2, 246-259. doi:10.1057/palgrave.jba.2950045

\section{Keywords:}

collapse, inspection, pathology, methodology

\section{INTRODUCTION}

At around 2.00pm on 1st August, 1995 a 26-year-old office building in Ashford, Middlesex, a few miles from Heathrow Airport, collapsed and killed the four men who were working within the building at the time. At that time, 23 people were working on the site.

The building had been constructed for Wickens Holdings Ltd around 1969. It was $25 \mathrm{~m}$ wide and $9 \mathrm{~m}$ deep and was originally a single-storey building (Hollis, 1997). Some months later, perhaps as long as a year (Bingham, 2000), Wickens arranged for two further floors to be added on top of the single-storey structure. When completed, the building comprised four bays of about $5 \mathrm{~m}$ width plus a further $7 \mathrm{~m}$ cavity brick and block core containing toilets and the staircase (Figure 1).

The four-bay east side of the completed building was constructed with brick piers supporting steel beams over the window openings, with pre-cast concrete slabs or planks laid across the width of the building, all of which were supported on the steel beams (Figure 2a and e). The brick piers ran through the height of the building, but were 


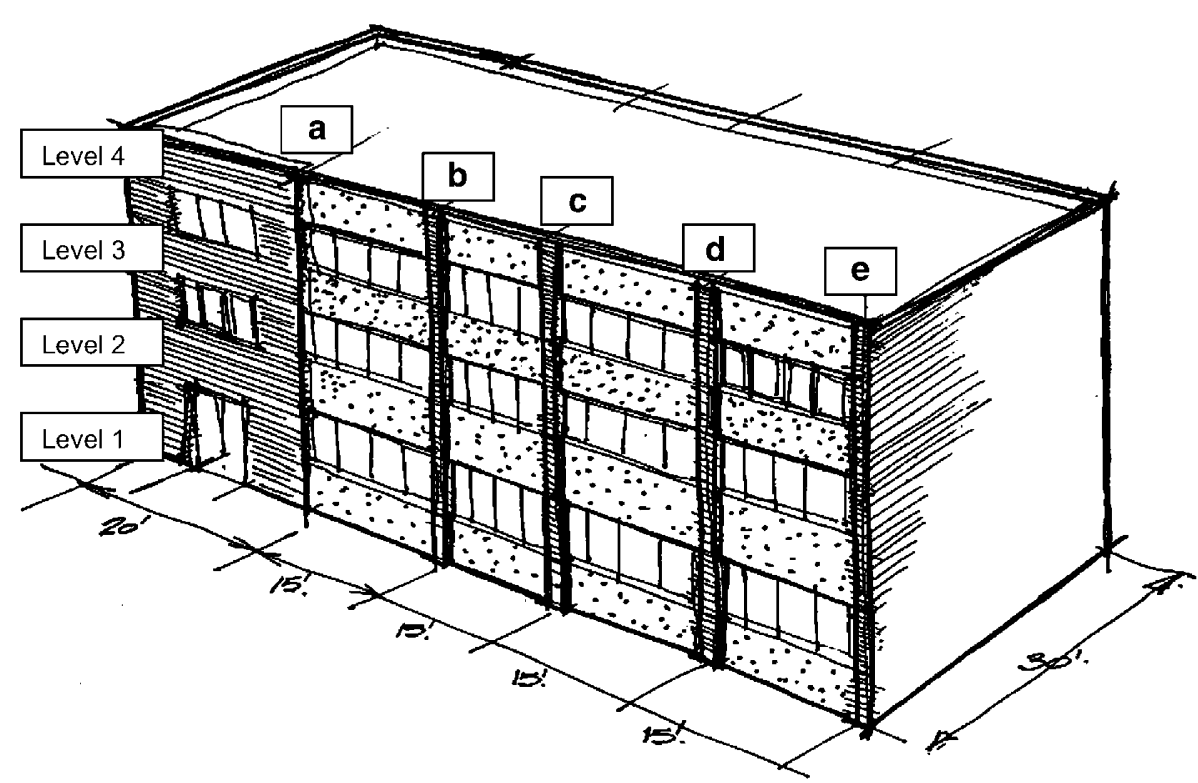

Figure I: Sketch of south face of the building before refurbishment work began in 1995. Dimensions in feet ( 15 feet equals $4.56 \mathrm{~m}$ ). Alphanumeric code to reference locations

interrupted on both first and second floors by the steel beams and floor planks. The west end of the building was constructed in cavity brick and block construction.

There were marked weaknesses at the floor junction with the brick piers and to the head of the ground floor where the piers were raised on top of a $100 \mathrm{~mm}$ block that had been part of the former first floor building's parapet (Figures 2c, d, f and g).

The property had been in use for 25 years. At the end of that period of use the then owners, Hall \& Co, decided to refurbish this building and rebuild the building located close to the south of this property. The building was inspected by structural engineers who determined that the brick piers were overstressed and that there was a need to add additional columns to the mid span of each bay. To place these new stanchions in position, the block apron below the windows had to be cut through to provide room for the stanchions. The initial intention was that a chase be cut, but the brittle nature of the blocks prevented this. The second approach was to cut a vertical space through the blockwork. Ultimately it was decided that the block panels would have to be removed in total to effect a satisfactory repair (Berwick, 2000). These panels, because of weaknesses in the construction of the building, were integral to the load distribution within this building.

Although these alterations were being carried out after the introduction of the CDM Regulations, the work did not have to comply with them because it had been started before 31st March, 1995, the deadline identified in the Act (CDM, 1994). The CDM Act required that the planning supervisor gave priority to measures that will protect all persons at work who may carry out construction work (CDM, 1994, s.13). No propping was installed to the interior or exterior of the building at any time during the course of the work. The adjoining office building was demolished and had been rebuilt as a two-storey office building that linked into the original building around the entrance in the brick and block core.

At the time of the collapse, workmen were in the process of replacing the timber windows, cutting out the block walling (Witness Statements, 1996) below the windows to make room for the addition of the additional steel columns (at the mid span of each of the 

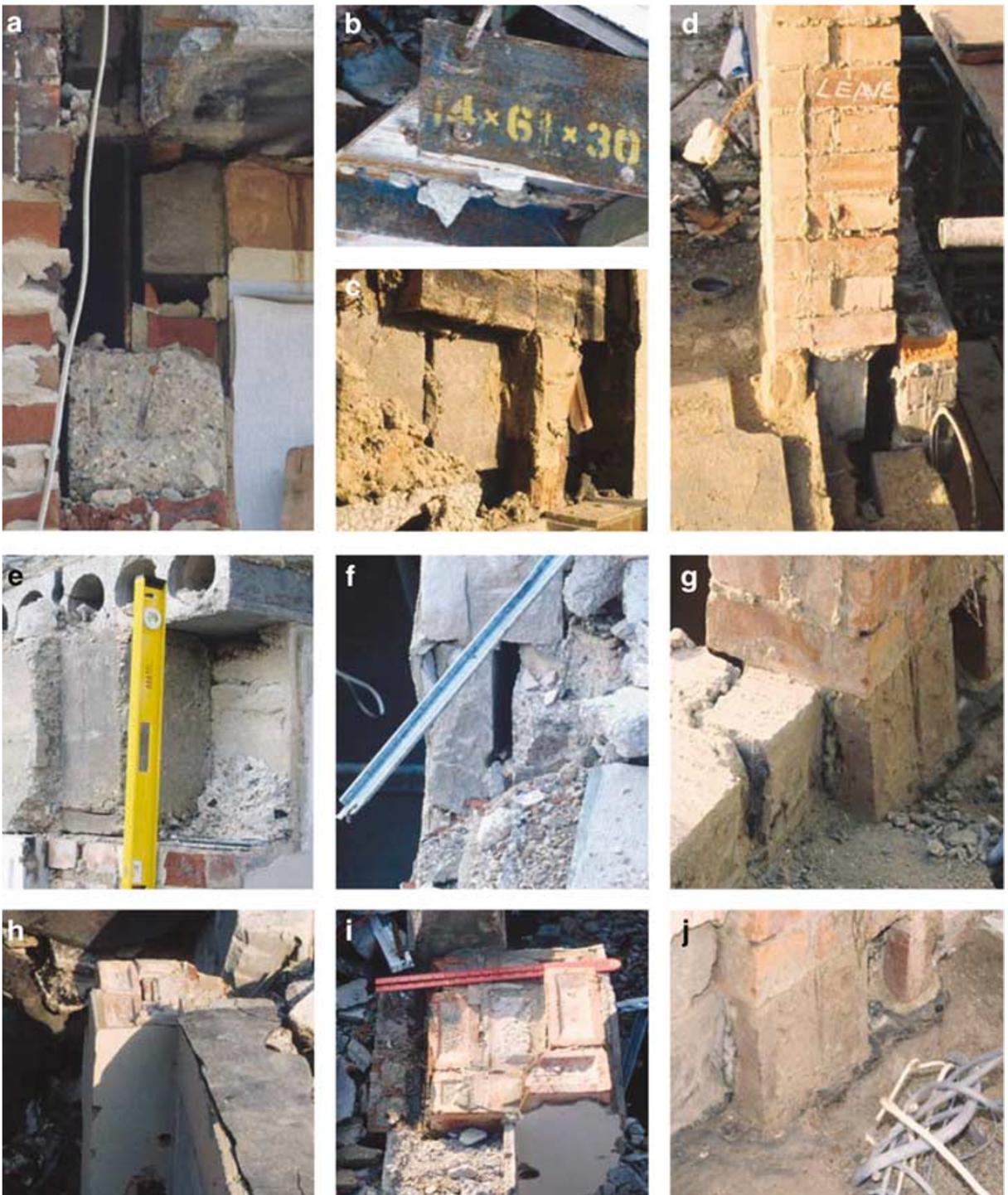

Figure 2: A selection of photographs taken during the deconstruction of the building showing the steels (and dimensions) (b), the support for pier A2 (c), (d), (f), (g) and (j), brick pier dimensions (h) and (i) and a steel-encased beam at BI/B2 (e)

four bays). New pad foundations had been cut out at ground floor level to support these new columns. The removal of the windows and the cutting through the blockwork apron below the windows to insert the steel columns weakened the building. The rigidity afforded by the block panels below the windows was lost with their removal (Berwick, 2000).

The Investigation (HSE, 1999b) revealed serious defects in the original construction around what had been the head of the parapet of the former single-storey building. When the building was extended to three storeys, the lightweight concrete blocks forming the parapet wall were left in position and used to support the load-bearing columns at first floor level (Figure 3). It is believed that all of the brick piers had been built on top of the $100 \mathrm{~mm}$ wide concrete blocks that had formed the inside of the former parapet to the single-storey construction. 
The collapse is believed to have been caused by the failure of the block supporting column B at level 2 (first floor), leading to the sudden collapse of the four bays of the building (Figure 4) (HSE, 1999a, b). It is believed that when cutting away the apron blockwork at first floor level the presence of a $100 \mathrm{~mm}$ block was encountered. It is not known whether the vibration caused by the use of a Kango or similar rotary demolition hammer resulted in the failure of the blockwork at B2. The extent of the collapse was much greater than might have been expected because of the lack of structural continuity

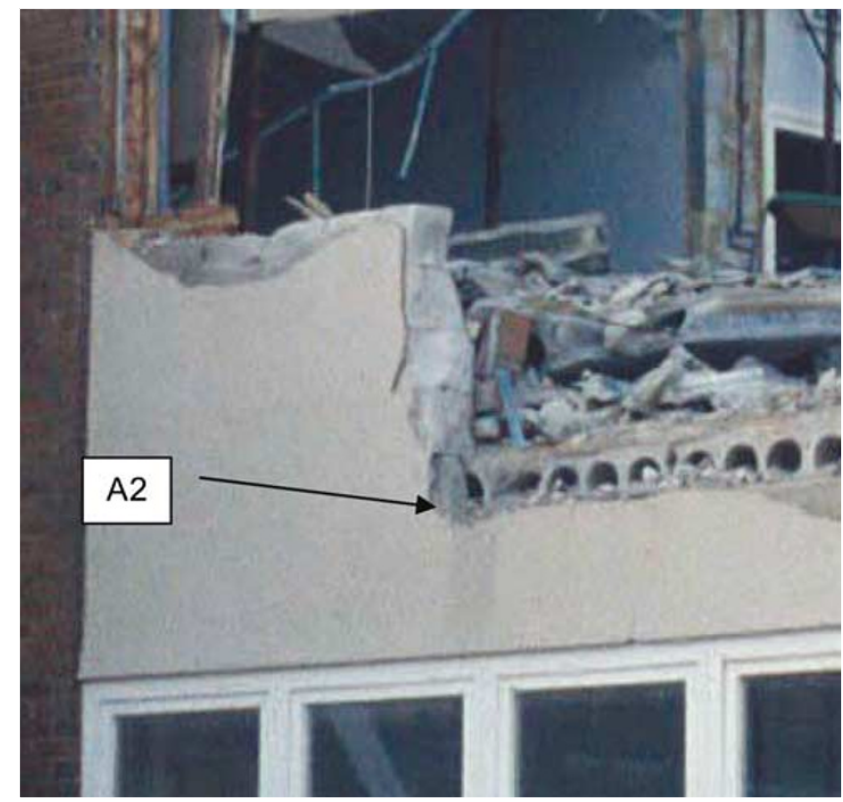

Figure 3: Photograph of part of the south elevation. The remaining ground floor section of the south elevation showing the block panel below the first floor window that had been cut through to form the channel for the new steel columns. The presence of the single-block part of the former parapet can be seen arrowed and sits at the end of the concrete Bison planks below the $200 \mathrm{~mm}$ infill apron panel. This section of blockwork was carefully deconstructed to reveal the remains of the construction at this point. An assumption has been made that similar construction was present to the remainder of the building
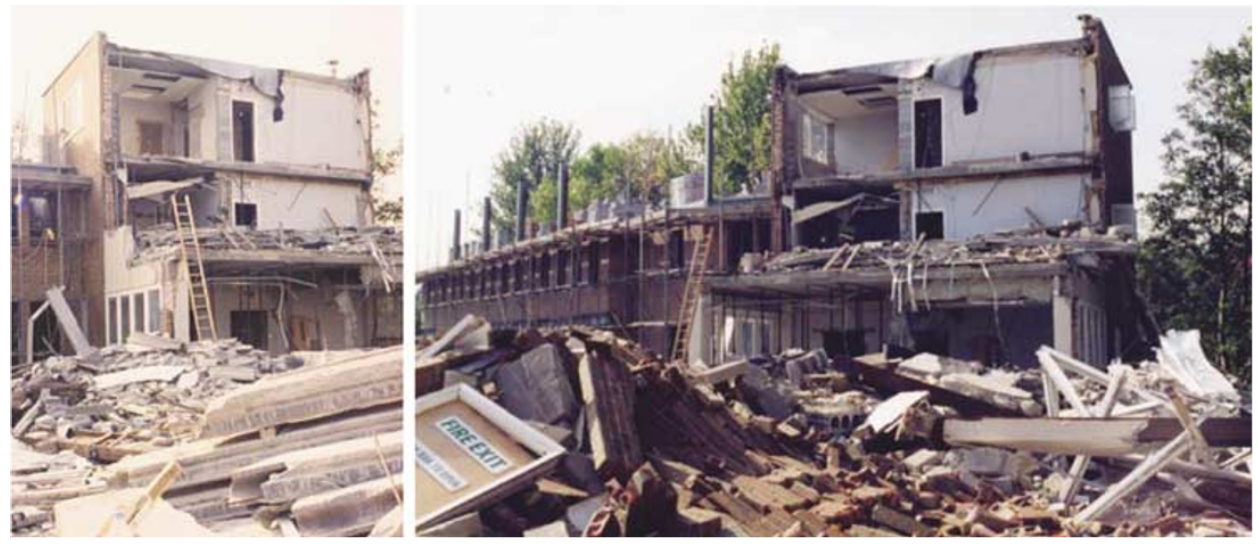

Figure 4: The building after the recovery of the bodies 
(ties) between key structural elements (HSE, 1999b) leading to a lack of redundancy in the structure as designed.

The purpose of the subsequent investigation was to establish the sequence of events that led to the collapse, the cause of the accident, and the lessons that could be learned by this failure and the subsequent inquest ${ }^{1}$ and Court case (Berwick, 2000) to determine who was liable.

The quality of the construction was not investigated to any significant degree prior to the works being started. Had there been a surface examination, the existence of the remains of the former parapet blockwork would not have been found. The brittle nature of the construction should have been identified together with the general risk that such a type of construction presented. It is suggested that such a consideration of risk should have resulted in a change in the method of work adopted by the contractor.

\section{METHODOLOGY OF INVESTIGATION}

The investigation was planned to collect information in stages. The main aim was to establish the facts of the matter, identify the construction that had been used, as well as exploring the history of the building from its design to collapse.

The first stage was an analysis of the evidence available shortly after the collapse of the building. The results of that information resulted in the decision to deconstruct the remainder of the building. There followed the analysis and testing of the remains of the building and the materials that had been used in its construction. The final stage was to verify the conclusions that had been reached by testing and modelling.

\section{Static analysis}

- A surface examination of the remains of the building.

- Examination of the drawings prepared prior to the original construction.

- Consideration of the evidence from the Pathologist's reports (Ratcliffe, 1995).

- Examination of Witness Statements.

- Aerial photographs of the building in 1970 and 1995.

Dynamic analysis

- Deconstruction of the remains of the building in a systematic manner to collect information on materials and their performance.

- Testing materials used to determine if they were of the standards expected.

- Calculate the expected performance of the components and compare load paths and load bearing capacity with the loads anticipated.

\section{Verification}

- Test the stability of the construction that existed prior to the alterations.

- Modelling to track the vulnerability of the construction to partial failure.

- Epidemiology - analysis of the cause of building failures and collapses.

- Pathology - research into studies of the cause of such failures.

\section{Determination}

- Determination of collapse sequence.

- Cause(s) of the collapse. 
- Determination of discovery of weakness prior to collapse.

- Identification of lessons to be learned from the collapse.

\section{OUTCOMES OF THE INVESTIGATION PROCESS}

\section{Information from pathology reports}

The Pathologists' reports (Ratcliffe, 1995) on the bodies recorded, among other things, what they were wearing (absence of hard hats, protective clothing or footwear), their health at the time of death and the levels of alcohol in their bodies. The blood alcohol levels were considered in the investigation because the accident happened after lunch time and alcohol could have affected the judgment or skill of anyone using cutting equipment or Kango (rotary percussion hammer). Careless use of such equipment could have contributed to the collapse. The reports also listed the names and occupations of those who died (site manager, contractor, carpenter and labourer). The manager was responsible for the new building to the south of the collapsed property and the upgrade of the building that collapsed.

\section{Position of the bodies and tools being used}

Three bodies were found (Witness Statements, 1996) close together (near C2) and the fourth on the first floor close to the east end where there was an external staircase. There was no record ${ }^{2}$ of what equipment was being used at the time of the accident. Witness Statements (1996) refer to the use earlier that day of percussion drills (Jack hammer or Kango) to break out block panels below the windows. If that were to be correct, then considerable vibration would have been caused by this method of working. No crushed or damaged Kango or equivalent piece of equipment was found in the debris. As no tools were found, it is assumed they were removed by the contractors, stolen by those able to gain access to the site during the rescue or up to the time the site was sealed, or that no tools were used in the work. The latter was considered to be unlikely. The cessation of trading of the contractor hindered access to information.

\section{Evidence from Witness Statements}

Witness Statements were taken from those who had worked at the site during the alterations and those who 'witnessed' the collapse of the building. The documents recorded the impressions of those who had been in the building of the work being carried out and of the methods and materials being used. A problem with Witness Statements is that they are a record of what people believe that they remember. It will be noted that the statements were taken nearly a year after the event. In order to evaluate the evidence produced, one has to look at the conflicts in the evidence supplied.

For example - there were suggestions that the building was distorted before the collapse took place. Many of the statements referred to the piers on front elevation being distorted and leaning outward at first floor level, leading to most of the witnesses concluding that the building had been built out of plumb. Column $\mathrm{C} 2$ was kinked in and was not straight (Derek Butler: '5 inches inward kink by 2 to 3 inches'; Cooper: ' 1.5 inches'; Kingsfold: 'irregularity'; DeLasalle: 'quite a bit of distortion, building all over the place, 2.5 to 3 inches out of plumb'; Brian Cooke and repeated by Roger Barriball: 'building not plumb all the way up by about 2 inches looking B2 to F2'; James McAvoy: 'cracks inside at bottom of pier'; Richard Cooper (September, 1994): 'pier C2 undulated towards building'). The examination of the remainder of the building, however, did not 
support these statements. If anything, the remains should have been in a worse state than those that pre-existed the partial collapse.

The information about the work in progress on the day of the collapse suggested that the panels on the first floor, near the middle, were being cut away. Based on Figure 1, C2-D2 had been completed and they were working on E2 (Carl Webb 16th July, 1996, Stefan Aldred). Mark May and Stefan Aldred's evidence referred to the use of hammer and an electric Kango to remove panels under windows first-floor C2/D2. There was a reference to the Kango being silent just before collapse (various including Butler, May, McAvoy).

Evidence was also given as to where the people who died were at the time of the collapse. Martin's body was found at the bottom between C2/D2. A second body (Barnes) was found a metre towards D2, nearer centre of building. Both bodies were recovered from the ground floor level (but so was everything at this stage). Part of one of the bodies was found on the first floor.

Many of the Witness Statements dealt with what the witness recalled having seen immediately before the collapse. One witness wrote that he saw a hole in the brick pier 10 inches wide 2-3ft above the floor and that the blockwork had come away from the pier. A hole had been there before and had been covered by the blockwork (Mark May). Under cross-examination, this evidence changed to place the hole at one foot above the floor and a recollection that within the hole the witness had seen that the pier was saddled over the block former parapet wall in the same way as the remaining 'pier' between non-collapsed brickwork and remains of sub-first-floor window panel B2/C2 (Mark May) (See Figure 2c and d).

The evaluation of the Witness Statements suggested that they corroborated the findings of the evidence obtained from the deconstruction of the building. Unfortunately, that information would have been circulated within those who provided statements, and, whether intentionally or not, may have influenced the recollection of the witnesses.

It is noted that guidance on taking Witness Statements records that Witness Statements (CJA, 1967) should normally be taken as soon as possible to ensure that

- the events are still fresh in the mind of the witness;

- the evidence is recorded before the witness is tempted/has opportunity to discuss their evidence with others.

\section{Conclusion from Witness Statements}

- The building collapse was due to defective construction in 1969 and alterations being undertaken in 1995, which destroyed a defective brick pier.

- It is doubtful/unlikely that a detailed examination would have revealed that there was not a continuous ring beam in the ground floor lintel.

- The varied construction, the acknowledged defects in the building and the distortion may have suggested that the building was weaker than believed and indicated a need to prop the building before inserting a new steel frame.

\section{Evidence from deconstruction}

The systematic deconstruction and recording of the remainder of the building that did not collapse identified a number of factors. This work also involved collecting and organising 

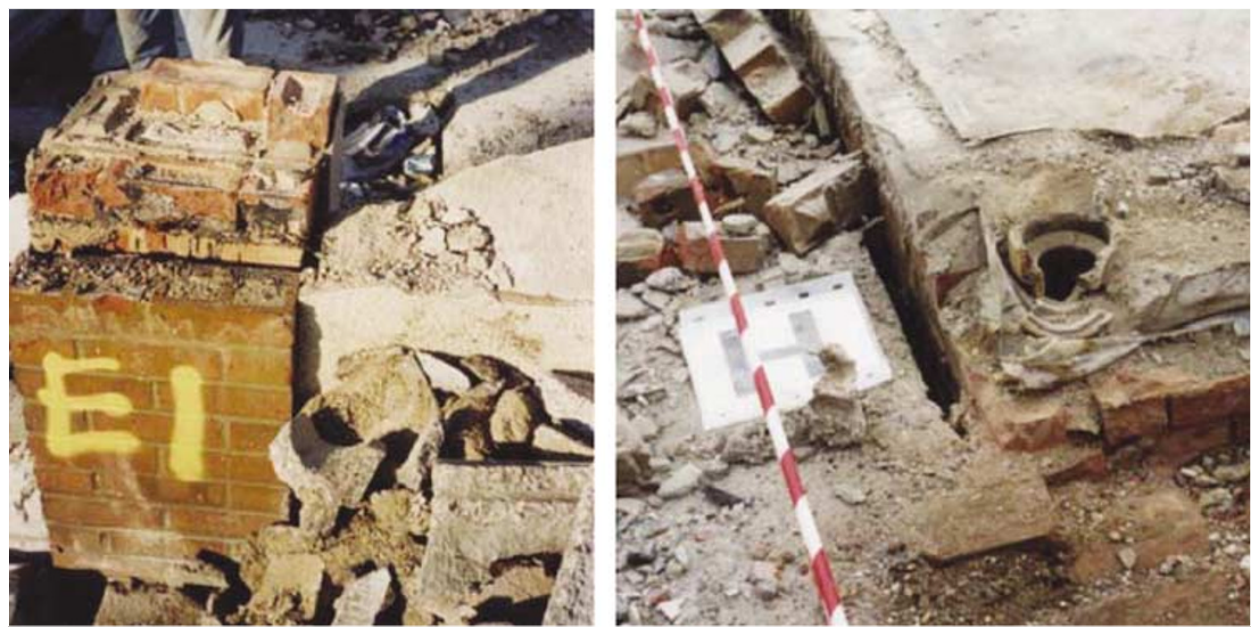

Figure 5: The base of pier $E$ and the detail of the floor slab with gully below

recognizable debris. The disassembly of the remainder and recording the quality and nature of the construction provided factual evidence of the build quality in the construction at the transition between the upper floors and the original first floor construction, variations in pier dimension (from debris), the size of steel beams used, as well as the standards of building and of the materials used (Figure 2).

The drawings did not show the detail of the rainwater discharge from the roof. The rainwater down pipes ran alongside two of the brick piers and discharged into gullies located beneath the piers (Figure 5). The material that had been repositioned during the period of recovery of the bodies was examined and tested to determine whether there was a fault in the manufacture of the Bison beams, defects in the concrete, mortar, steel or bricks used. The crushing strength of bricks and blocks could be established, but not the quality of those bricks and blocks that may have been in a critical location within the building prior to the collapse.

\section{Unreliability of original drawings}

The original drawings of the 1969 development comprised floor plans and sections that contained limited detail. There were two sections through the proposed construction, one showing a three-storey building and one showing a single-storey building together with its floor plan. The ground floor plan of the single-storey building shows provision for a staircase and a temporary roof over (Figure 6).

The drawings showed construction that was not present in the completed building. The lintel over the ground floor windows was intended to have been a reinforced concrete. One assumes that had such a beam been installed, it would have been a single beam across the width of the elevation, serving all four bays. The lintel installed was a concrete encased steel beam installed as individual lintels over each bay opening. The lintels to higher levels were all shown to have been designed to be reinforced concrete when steel beams (not encased in concrete) were used. This resulted in the building that was constructed being more vulnerable to total collapse than that which had been designed.

The brick piers were not built to the dimensions shown on the drawings. The brick piers should have been $455 \mathrm{~mm}$ square, but were effectively $455 \mathrm{~mm}$ by $340 \mathrm{~mm}$ to the ground floor, because the front face of each pier was not tied to the remainder being separated from the body of the pier by a bitumen skin, applied, one assumes, as a 


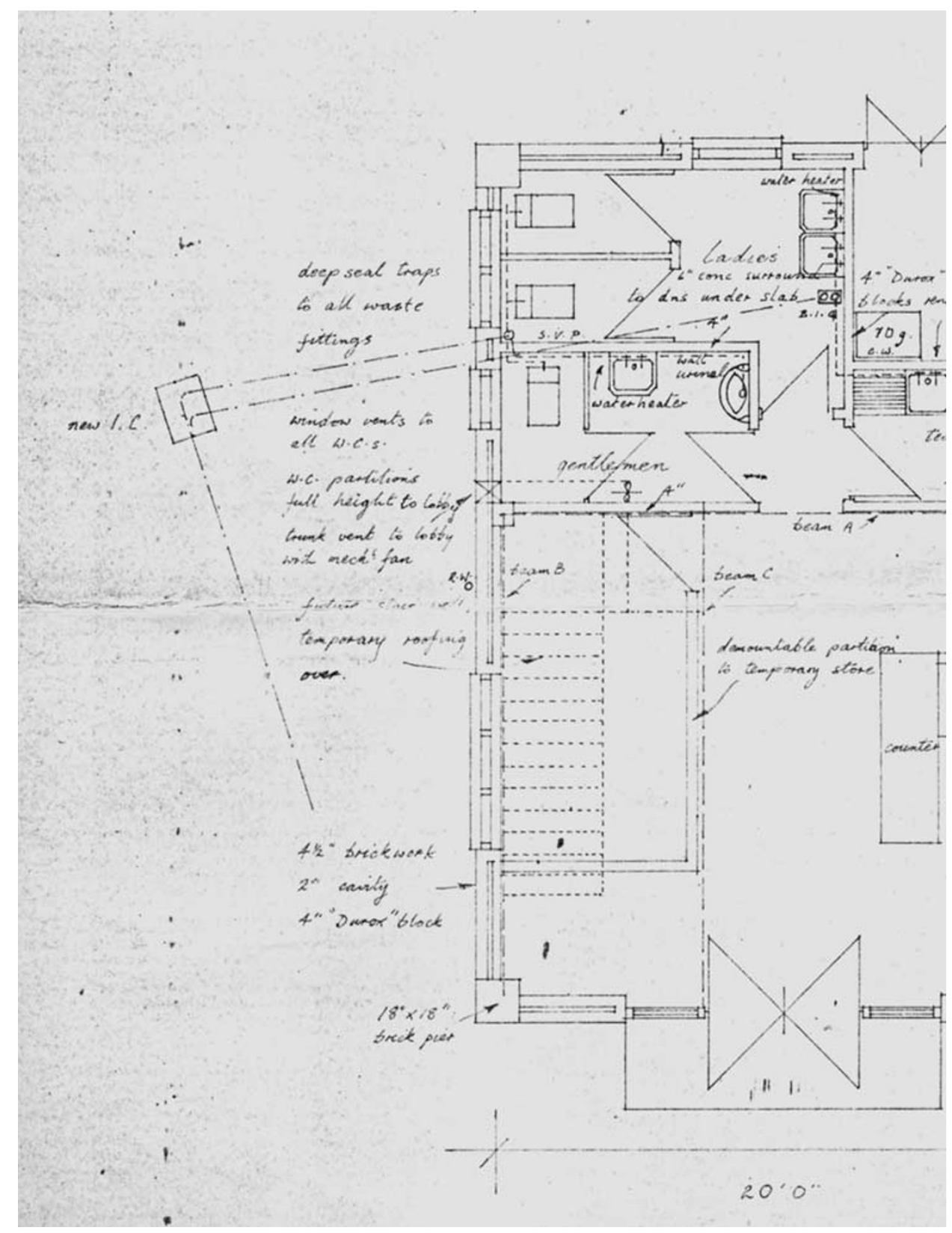

Figure 6: Single-storey plan. A temporary store with a demountable partition is shown in the area of the future staircase that has been dotted in position on this plan. The annotations on the plan include 'Future stairwell, temporary roof over', 18" by 18 " brick pier (that is about $450 \mathrm{~mm}$ by $450 \mathrm{~mm}$ or 2 bricks wide by 2 bricks long). The inner leaf of the cavity wall and internal partitions are all shown to be $100 \mathrm{~mm}$ Durox blocks

damp-proof membrane. To the upper floors the effective depth of the piers was $230 \mathrm{~mm}$ (see Figure 2d). The upper brick piers were only 50 per cent of the area of the designed columns and those to the lowest level 75 per cent. As a result, each pier was less substantial than those shown on the design drawings. On the basis of the analysis of the information from the original drawings and the comparison with what was built, we note 
that old construction drawings should not be used as a reliable resource when considering how a building may have been constructed.

\section{Tainted site}

A building site where a death or deaths have occurred is not treated like a crime scene from the outset. The first priority of those who are there at the time is to rescue the injured and recover the bodies of the dead. The rescue services move and relocate the items that may be hiding the bodies, and may cut and damage parts of the debris that were unaffected by the collapse. The site when first inspected is not a reliable indication of what may have happened, where the fault may have occurred or of the performance or failure of any of the components. For example, the discovery of broken concrete planks does not mean that they broke prior to the collapse or during the collapse. In this case, they were broken in the process of the recovery of bodies.

For this reason, consideration should be given in the future to recording the evidence from the site at the earliest opportunity.

\section{Information from aerial photographs of the site}

Aerial photographs are taken on a regular basis depending upon where a building is located and most major urban areas are photographed at least annually. Archive pictures are available from the beginning of 1970 (Figure 7). These pictures revealed the following information:

- There was evidence to suggest poor maintenance (visible ponding on the main roof around the rainwater drops).

- The trees surrounding the site had expanded, and more trees were present at the time of the collapse.

- The building across the railway line running along the north boundary of the property had been demolished and a new and larger building had been erected.

- The cars had been parked (in the earlier photograph) against the south wall.
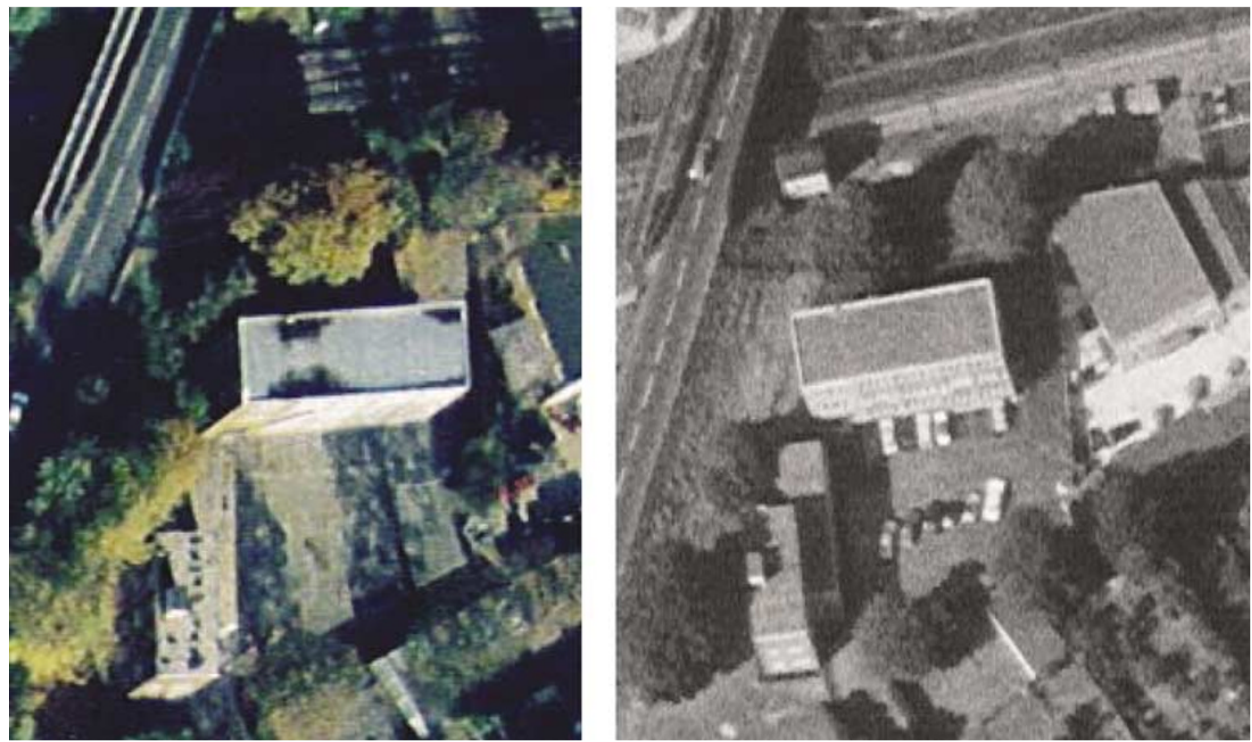

Figure 7: 1995: rainwater outlets blocked (left) and 1970: cars parked against south wall (right) 
This type of structure, even without the presence of the block parapet, was vulnerable to failure had it suffered impact damage, such as may have resulted from a vehicle colliding with one of the piers on the south elevation.

\section{Result of collapse pattern modelling}

In order to test the theories of the vulnerability of the building to the partial loss of a single brick pier, a model was constructed to $1 / 25$ scale. The removal of a part of the brickwork of one column resulted in the progressive collapse of the whole building. The time taken between activation and collapse was less than one second.

\section{CONSEQUENCES OF THE CONCLUSIONS}

\section{Possibility of prior discovery}

The official report (HSE, 1999a, b) stated that 'Examination of the brick columns still standing at first floor level showed no externally visible signs of the lightweight concrete blocks in the columns. They had been effectively hidden by the facing brickwork, internal plaster and the inclusion of in-fill brickwork. These defects at the base of the columns at first floor level could not have been expected and therefore the assessment methods could not have been expected to detect what had been constructed'. The HSE report (1999a) stated that 'The defects discovered in the brick columns in this building reflect either gross incompetence or total irresponsibility on the part of those engaged in the original construction work and its management'.

\section{Public warnings issued as a result of collapse}

There are a significant number of buildings of a similar type that are still in use (Bingham, 2000; HSE, 1999a). As a result of the outcome of the investigation into the cause of this collapse, the UK Government issued a public warning concerning the risks attached to this type of construction (HSE, 1999a, b). They also drew attention to original construction drawings not being a reliable source of information about the method of construction or the materials that have been used and advised that they should not be relied upon without corroboration in the analysis of an existing construction (Hollis, 1997; Bingham, 2000; HSE, 1999a, b).

A structural appraisal should identify the vulnerability of such buildings on the following basis and recommend actions to be taken to reduce the potential risk. Clients, planning supervisors, contractors and their advisers when renovating, refurbishing, extending or demolishing a building, particularly (if the building was built before the Building (5th Amendment) Regulations 1970 took effect), should address the possibility that it may not be robust, and that damage to a key structural element could lead to a disproportionate collapse (HSE, 1999a, b).

The original developer of this site in 1969, Wickens Holdings, was found by the Court to be solely responsible for the death of one of the workmen (Bingham, 2000; Berwick, 2000) and ordered to pay compensation (Contracts Journal, 1995).

\section{REVIEW OF METHODOLOGY}

The process of diagnosing the cause of a defect should start with the establishment of reliable data. The lessons learned during this investigation included the recognition of the lack of reliability of Witness Statements and original construction documents from 1969. The majority of the reliable information came from the managed deconstruction of the 
remaining building. The brittle and vulnerable nature of a building constructed erroneously and designed to have no redundancy was revealed in the collapse pattern witnessed in the modelling of the failure.

This investigation identified the absence of reliable information about the method and quality of the original construction. The absence of adequate design drawings and site control caused the death of four people 26 years later. There is a need for all buildings to have some form of readily accessible time capsule that contains accurate information about the construction process.

The quality of much of the construction from the 1960s was of a modest standard, and there are many other buildings erected around that time, which may collapse in similar circumstances unless adequate precautions are taken during remedial work.

Buildings fail, not only because of how they are designed, but also because of how they were built and the management of a building during its life will also affect its life expectancy. But the greatest risk to a building may come when it is being upgraded to meet a new standard. Unless the quality of the building has been identified prior to that work, the risk of a major failure during that work cannot be avoided. For all the flaws that existed in this building it lasted 25 years. It failed when it was weakened in the process of it being made stronger.

\section{Cost-benefit analysis of investigation methods used}

The examination of the collapse of this building used a range of approaches to try and determine the cause of the failure, and from the information that was available at various times during the original construction, the design of the alterations, and the alterations themselves. The evidence was to be presented to the court for them to decide upon the liability of those who had been involved with the building over its lifetime.

In order to decide upon the effectiveness of the various methods attempted, an analysis of their cost and benefit were applied to produce a figure as an indicator of the value benefit of that piece of work (Table 1).

While this is an experimental approach to evaluation, its purpose is to set the various approaches alongside each other so that in the future the information that can be gleaned by differing approaches can be evaluated not only by the benefit but also by the cost. In all steps of investigation, the cost of knowing has to be balanced with the cost-benefit of the information acquired. One also has to take account of the misleading information that may be an outcome of certain work. In the future the outcomes in this area should be

Table I: Analysis of costs and benefits of different investigation techniques

\begin{tabular}{|c|c|c|c|c|c|}
\hline & Activity & Cost $f$ & $\begin{array}{l}\text { Benefit } \\
\text { positive }\end{array}$ & $\begin{array}{l}\text { Negative } \\
\text { results }\end{array}$ & $\begin{array}{l}\text { Value } \\
\text { benefit }\end{array}$ \\
\hline \multicolumn{6}{|c|}{ Primary analysis } \\
\hline I. & Inspection and recording of the remains of the premises & 800 & 3 & 4 & 5,333 \\
\hline 2. & Inspection of original construction drawings & 325 & 5 & 5 & 1,625 \\
\hline 3. & Aerial photographs & 250 & 4 & 2 & 625 \\
\hline 4. & Analysis of pathologists reports & 325 & 4 & I & 81 \\
\hline 5. & Analysis of Witness Statements & 1,300 & 5 & 3 & 3,900 \\
\hline 6. & Deconstruction of remains & 75,000 & 8 & I & 9,375 \\
\hline 7. & Testing of materials used in the original construction & 1,125 & 4 & I & 1,406 \\
\hline 8. & Analysis of past building failures & 1,250 & 2 & 3 & 9,375 \\
\hline \multicolumn{6}{|c|}{ Secondary analysis (depends upon results of other work) } \\
\hline 9. & Cross check construction drawings with materials on site & 1,100 & 6 & I & 183 \\
\hline 10. & $\begin{array}{l}\text { Load path analysis calculation based on building as } \\
\text { constructed }\end{array}$ & $\mathrm{I}, 150$ & 4 & I & 288 \\
\hline 11. & Modelling and testing of hypothesis & 2,400 & 6 & I & 400 \\
\hline
\end{tabular}


subject to close scrutiny to prevent lost money being spent on abortive work, but all investigation will end up with some wasted effort.

While it is hoped that future investigation into death caused by the collapse of a building may not be required, it is hoped that the lessons learned in this work may act as both a warning and a guide for future work in this field.

\section{Cost}

Cost refers to the time spent on the procurement and analysis together with such costs as may have been incurred, such as specialist contractors or equipment. Time has been calculated at a rate of $£ 75$ per hour. Dependent upon the expertise of the people used in the analysis, this may be an underestimate.

\section{Benefit}

The benefits of the research were weighted for their positive and negative results. A number was allocated for each piece of work based on the outcomes of the work in this building. Because the results could be misleading, the final assessment takes into account the wasted time that may have been lost because of misleading information being produced.

\section{Benefit - positive}

The benefit is based on a scale of 1-9 where 9 is high. Examples of the level of marks awarded are set out below. The distinction between items 8 and 9 may seem pedantic, but where work is carried out as part of a forensic analysis, there are differing levels of proof required in criminal cases than in civil cases. In criminal matters the requirement is for a matter to be established beyond reasonable doubt, whereas in civil matters the proof is required on a balance of probability. In the former there is a higher cost in being certain, in the latter a lower cost, but higher risk attached to the quality of supporting expert evidence.

1. Of no benefit at all in the final analysis.

2. Neutral results that neither assisted nor rejected a cause.

3. Eliminated a possible cause.

4. Offered assistance in directing future investigation.

5. Result in a clear guide as to future investigation.

6. Suggested a possible cause but no proof whatsoever, or identified proof of a weakness but not establishing proof of a cause.

7. Suggested a possible cause with subjective indication of possibility as to cause.

8. Suggested a specific cause but unable to establish adequate proof to be certain, but sufficient to be probably certain.

9. Identified a specific cause with proof beyond reasonable doubt.

\section{Negative consequences}

In much the same way as the assessment was made for the positive benefits of an investigation method, the negative outcomes were evaluated as well.

1. No misleading information identified (no weighting attached to this result).

2. Produced no result whatsoever of us to this investigation.

3. Clear guide as to future investigation that produced both positive and negative results in equal measure. 
4. Clear guide as to future investigation that produced more negative than positive results.

5. Suggested circumstances that influenced future investigation that were of no benefit.

6. Suggested a possible cause with subjective indication but which was incorrect.

7. Suggested a probable cause with subjective indication but which was incorrect.

8. Suggested a specific cause that it was reasonable to follow but which was incorrect.

9. Identified a specific cause together with significant substantiation but which was incorrect.

\section{Value cost}

The unit of benefit is calculated by identifying the unit cost per unit of benefit. The negative outcomes have been weighted (by a factor of 5) because of the problems caused by misinformation that can come from investigations that produce misleading results. (For example, the close inspection of the remains produced incorrect information, because the remains of the building had been disturbed in the rescue operation, and they were therefore not a prime source of information.)

\section{SUMMARY}

These results relate to the investigation of the cause of failure in one building. They are not results that will be achieved in all investigations. The results will have been heavily affected by the defect being an incorrect detail in the original building, which, one hopes, has not been repeated. It is therefore an atypical cause, as opposed to a routine defect repeated in many similar buildings.

While the brittle nature of the construction and the history of poor maintenance were not primary causes of the collapse, they, however, serve as a warning for those involved in the industry who come across similar types of building construction.

\section{Notes}

1 A unanimous verdict of unlawful killing was delivered at the inquest in 1996.

2 John Lay \& Co (Portsmouth) Ltd. ceased trading on 24th August, 1995 when their bank called in their overdraft because of their involvement in this building collapse.

\section{References}

Anon (1995) 'Weak structure claims four', Contract Journal, 11 August. Available from http://www.contractjournal.com/ Articles/1995/08/10/27567/Weak+structure+claims+four.html, Accessed 5th November, 2006.

Berwick $v$ Wickens Holdings, John Lay \& Co and R J Watkinson \& Partners, January 2000 (unreported).

Bingham, T. (2000) 'Column inches', Building, CCLXV(7), 67.

Criminal Justice Act (1967) LP70s — section 9.

Health and Safety Executive (1999a) Collapse of a Three-storey Building: HSE Investigation Report, Office of the Deputy Prime Minister, London.

Health and Safety Executive (1999b) Ashford Building Collapse: HSE Investigation Report, Office of the Deputy Prime Minister, London.

Hollis, M. (1997) Report on the cause of the collapse of 47 Woodthorpe Road, Ashford (private papers).

Ratcliffe, N.A. (1995) Pathologists reports (3 August) on the bodies of Messrs Martin, Barnes, Berwick and Malloy, deceased.

The Construction (Design and Management) Regulations (CDM) (1994) No. 3140 (made 19th December, 1994 came into force 31st March, 1995).

The Construction (Design and Management) Regulations (CDM) (1994) Sect 13(2).

Witness Statements (1996) of both Mark May and Stefan Aldred 'they were using hammer and electric Kango to remove panels under windows to first floor' (location C2/D2) 16 July. 